\title{
A climatological study of the relations among solar activity, galactic cosmic ray and precipitation on various regions over the globe
}

\author{
Sourabh Bal and M Bose* \\ Department of Physics, Jadavpur University, Kolkata 700 032, India. \\ *e-mail: mridulbose@gmail.com
}

\begin{abstract}
We apply Fourier and wavelet analyses to the precipitation and sunspot numbers in the time series $(1901-2000)$ over Australia $\left(27^{\circ} \mathrm{S}, 133^{\circ} \mathrm{E}\right)$, Canada $\left(60^{\circ} \mathrm{N}, 95^{\circ} \mathrm{W}\right)$, Ethiopia $\left(8^{\circ} \mathrm{N}, 38^{\circ} \mathrm{E}\right)$, Greenland $\left(72^{\circ} \mathrm{N}, 40^{\circ} \mathrm{W}\right)$, United Kingdom $\left(54^{\circ} \mathrm{N}, 2^{\circ} \mathrm{W}\right)$, India $\left(20^{\circ} \mathrm{N}, 77^{\circ} \mathrm{E}\right)$, Iceland $\left(65^{\circ} \mathrm{N}, 18^{\circ} \mathrm{W}\right)$, Japan $\left(36^{\circ} \mathrm{N}, 138^{\circ} \mathrm{E}\right)$, United States $\left(38^{\circ} \mathrm{N}, 97^{\circ} \mathrm{W}\right)$, South Africa $\left(29^{\circ} \mathrm{S}, 24^{\circ} \mathrm{E}\right)$ and Russia $\left(60^{\circ} \mathrm{N}\right.$, $100^{\circ} \mathrm{E}$ ). Correlation analyses were also performed to find any relation among precipitation, sunspot numbers, temperature, and cloud-cover at the same spatial and temporal scale. Further correlations were also performed between precipitation with electron and proton fluence at the time interval, 1987-2006. All these parameters were considered in annual and seasonal scales. Though correlation study between precipitation and other parameters do not hint any linear relation, still the Fourier and wavelet analyses give an idea of common periodicities. The 9-11 year periodicity of sunspot numbers calculated by Fourier transform is also confirmed by wavelet transform in annual scale. Similarly, wavelet analysis for precipitation also supports the short periods at $2-5$ years which is verified by Fourier transform in discontinuous time over different geographic regions.
\end{abstract}

\section{Introduction}

Solar energy drives the Earth's climate system, and has the potential to directly alter climate from the decadal to century scale fluctuations was verified by Eddy (1976). Precipitation influences the atmospheric circulation through the provision of energy to the surrounding air in the form of latent heat released in the condensation process. A good understanding of long-term precipitation variability is essential for the management of water resources and agriculture. The importance of rainfall variability for the global and regional scale depicts to know the variability of the rainfall for long periods as function of the natural and anthropogenic forcing. Much scientific effort has been experienced in trying to understand how much influence the Sun exerts on Earth's precipitation. Here, we highlight some of the recent scientific researches on such solar linkage with precipitation. Reid (1991) looked at the record of the global average sea surface temperature and noticed a striking similarity with the long-term variations of the solar activity. In 1999, Reid also stated that effects on the surface environment could have direct impact on everyday life, such as variations in the stratospheric ozone layer. Clayton (1923) investigated rainfall data from stations at different latitudes during 1860-1917 and found increased precipitation exists in the equatorial regions and decreased precipitation in the mid-latitude during solar maximum. Polar regions may have increased precipitation. Clayton (1923) also pointed out that at continental, mid-latitude stations, winter rainfall is negatively correlated and summer rainfall is positively correlated with solar cycle. Xanthakis (1973) showed annual excess precipitation as a function of the 11-year solar cycle between $40^{\circ}$ and

Keywords. Solar activity; precipitation; Earth; galactic cosmic rays. 
$90^{\circ} \mathrm{N}$ and found positive and negative correlations depending on the latitudinal as well as longitudinal bands and the time intervals. Cloud cover plays an important role to influence precipitation. Dickinson (1975) first pointed out the possibility of processes by which the ionization effects due to galactic cosmic rays affect sulphate aerosol formation and lead to cloudiness. Svensmark and Friis-Christensen (1997), Svensmark (1998) studied the correlation between global cloud cover and the cosmic ray flux. Verschuren et al (2000) presented a decade-scale reconstruction of rainfall and drought series in equatorial east Africa over the past 1100 years. Hiremath and Mandi (2004) and Hiremath (2006) found that Indian rainfall is correlated with the sunspot activity and the occurrence of rainfall is high compared to the period of high sunspot activity. Zhao et al (2004) and Zhao and Han (2005) reported that annual precipitation in the Beijing area is closely related to the variation of sunspot numbers, and the solar activity probably plays an important role in influencing the precipitation on land. Echer et al (2008) who, studied wavelet analysis of southern Brazil rainfall series concluded that El Nino Southern Oscillations (ENSO) is responsible for its rainfall variability.

The Sun is not the only source of energetic particles that penetrate the Earth's atmosphere. Galactic cosmic rays (GCR), which are mostly protons and alpha particles, have typically higher energies but lower fluxes than the solar cosmic rays. The most impressive modulation is the 11-year variation that shows a clear anticorrelation with the 11-year solar cycle, as reported by Bazilevskaya (2000). Usoskin and Kavaltsov (2008) discussed a possible link connecting solar activity and climate variations to cosmic rays and the physicalchemical changes they produce in the atmosphere. Therefore, it is important to study the influence on precipitation due to solar energetic particles and galactic cosmic rays.

Recent studies reveal that it is difficult to explain the influence of solar variability on precipitation. We know that the Sun is responsible for climate system in a dominant way. Since the Sun, by far, is the largest supplier of energy to the Earth, it could influence the climate on Earth. Along with this, there may be other forcing activities, which influence the precipitation at the same time. So, it has become increasingly crucial to determine the relative importance of solar variation on climate. On the other hand, a good understanding of longterm precipitation variability is essential for the management of agriculture, water resources and land use. Therefore study of the variation of annual precipitation is also significant. Having in mind these different studies and mechanisms which can affect the precipitation on a given place, we have investigated, using correlation study, the influence of solar activity, cloud cover, temperature on precipitation over a period of 100 years (1901-2000). We have also studied the influence of electron and proton fluence on precipitation. We applied Fourier as well as wavelet techniques to determine the periodicity of precipitation for different regions as well as sunspot numbers to understand the role of natural driving forces in controlling the rainfall variability over the globe.

\section{Data}

The monthly precipitation, temperature and cloud cover for the stations, Australia $\left(27^{\circ} \mathrm{S}, 133^{\circ} \mathrm{E}\right)$, Canada $\left(60^{\circ} \mathrm{N}, 95^{\circ} \mathrm{W}\right)$, Ethiopia $\left(8^{\circ} \mathrm{N}, 38^{\circ} \mathrm{E}\right)$, Greenland $\left(72^{\circ} \mathrm{N}, 40^{\circ} \mathrm{W}\right)$, United Kingdom $\left(54^{\circ} \mathrm{N}\right.$, $\left.2^{\circ} \mathrm{W}\right)$, India $\left(20^{\circ} \mathrm{N}, 77^{\circ} \mathrm{E}\right)$, Iceland $\left(65^{\circ} \mathrm{N}, 18^{\circ} \mathrm{W}\right)$, Japan $\left(36^{\circ} \mathrm{N}, 138^{\circ} \mathrm{E}\right)$, United States $\left(38^{\circ} \mathrm{N}, 97^{\circ} \mathrm{W}\right)$, South Africa $\left(29^{\circ} \mathrm{S}, 24^{\circ} \mathrm{E}\right)$ and Russia $\left(60^{\circ} \mathrm{N}\right.$, $100^{\circ} \mathrm{E}$ ) from 1901 to 2000 is obtained from Mitchell et al (2002, 2004), Mitchell and Jones (2005). Here seasonal months are taken as follows: MarchMay (MAM), June-August (JJA), SeptemberNovember (SON), December-February (DJF) and annual mean data. The units for climatic parameters are: precipitation in $\mathrm{mm}$, temperature in ${ }^{\circ} \mathrm{C}$ and cloud cover in percentage. Observations from meteorological stations were assimilated onto grid covering the land surface of the Earth. Here the gridded data were transformed into 'country' averages by allocating each $0.5^{\circ}$ grid-box to a single 'country' and calculating the weighted mean of the constituent grid-boxes of each 'country'. The database is checked for inhomogeneity in the data observed at different stations using an automated method that refines previous methods by using incomplete and partially overlapping records and by detecting inhomogeneity with opposite signs in different seasons. The method includes the development of reference series using neighbouring stations. The present dataset has been developed which contains month by month variations for each 'countries'. The time series of precipitation and temperature were obtained from observations and the time series of other variables rely on a combination of observed data and synthetic data estimated using predictive relationships with temperature and precipitation. The seasonal and annual values are the means of their constituent months. One climate season (December-February) overlaps from one calendar year to the next. The following value begins in the December of the year recorded and ends in the February following the year recorded. The annual and monthly sunspot numbers for the same period are taken 


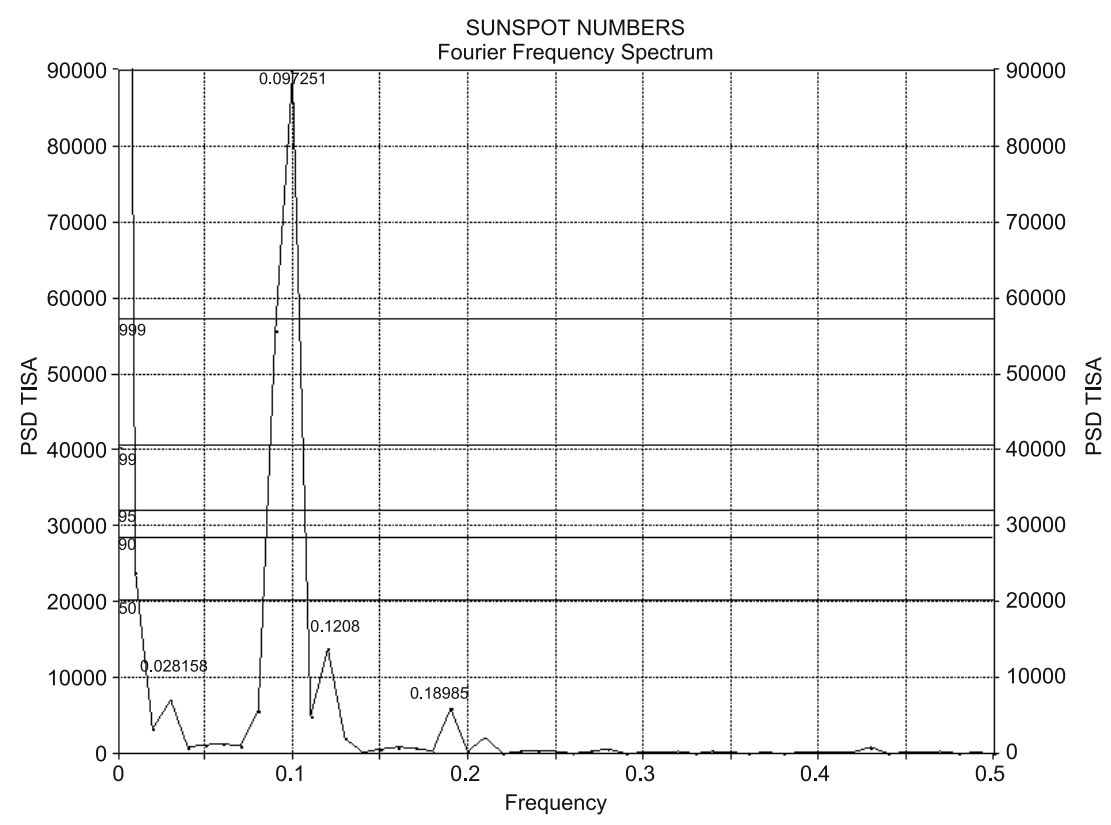

Figure 1. Fourier analysis of annual sunspot numbers. The frequency is plotted in x-axis and the power (time integral squared amplitude, TISA) is in y-axis. Sunspot numbers show periods at 5.3, 8.2, 10.2 and 35.5 years.

from Solar Geophysical Data Center (SGDC) of National Oceanic and Atmospheric Administration (NOAA) and National Geophysical Data Center (NGDC) of USA (Hiremath and Mandi 2004; Hiremath 2006). Daily Proton and electron fluence (1987-2006) are obtained from NOAA and NGDC. The electron detector on Geostationary Operational Environmental Satellites (GOES) measures the electron fluence. The units are electrons $/ \mathrm{cm}^{2}-$ year. Proton fluence are provided for $>100 \mathrm{MeV}$ protons. The units are protons $/ \mathrm{cm}^{2}$-year.

\section{Wavelet analysis method}

The Fourier analysis is used to investigate common periodicities between two series of data while wavelet analysis is used to analyze non-stationary time series. A way to analyze non-stationary time series, wavelet analysis, permits an automatic localization of objects such as periodic cycle sequence in time and frequency domain. It permits to identify the main periodicities in a time series. By varying the wavelet time scale and translating the scaled versions of the wavelet, it is possible to build a graph showing the amplitude versus frequency (or scale) and how they vary with time. In this investigation, Mexican hat wavelet (Derivative of Gaussian, DOG, $m$ (derivative) $=6$ ) is used because the peaks appear very sharp in the time direction, yet are more elongated in the scale direction. The Mexican hat wavelet is real valued wavelet functions, where the imaginary part is zero. For the wavelet spectrum, significance level for each scale is estimated, using values inside the Cone of Influence (COI), which is the region of the wavelet spectrum in which edge effects become important. It is defined as the $e$-folding time for the autocorrelation at each scale of the wavelet power. The e-folding time is chosen such that the wavelet power for a discontinuity at the edge drops by a factor of $e^{-2}$ and ensures that the edge effects are negligible beyond that point (Torrence and Compo 1998).

\subsection{Wavelet analysis of sunspot numbers}

Fourier spectra of sunspot numbers give periodicity at $5.3,8.2,10.2$ and 35.5 years is represented in figure 1. Figure 2 shows the wavelet power spectra for sunspot numbers. The upper part of the figure 2 shows time variation of sunspot numbers and lower part shows the result of the wavelet analysis of the period between 2 and 128 years. Contour lines delimit the periods significant at 95\% confidence level. The parabolic curve delimits the cone of influence region. The wavelet spectrum of sunspot numbers shows strong periods between 9 and 11 years (Zhao et al 2004; Zhao and Han 2005; Echer et al 2008) for the entire time span and agrees with Fourier analysis. This result is true for seasonal sunspot numbers (not shown) and agrees with Fourier spectra results at 10.2 years. Other periods of the wavelet spectra are under the cone of influence, and thus are insignificant. Many previous studies based on Fourier and wavelet studies of sunspot numbers reveal 11, 22 and 78-year periodicity (Zhao et al 2004; Zhao and Han 2005; Echer et al 2008). 

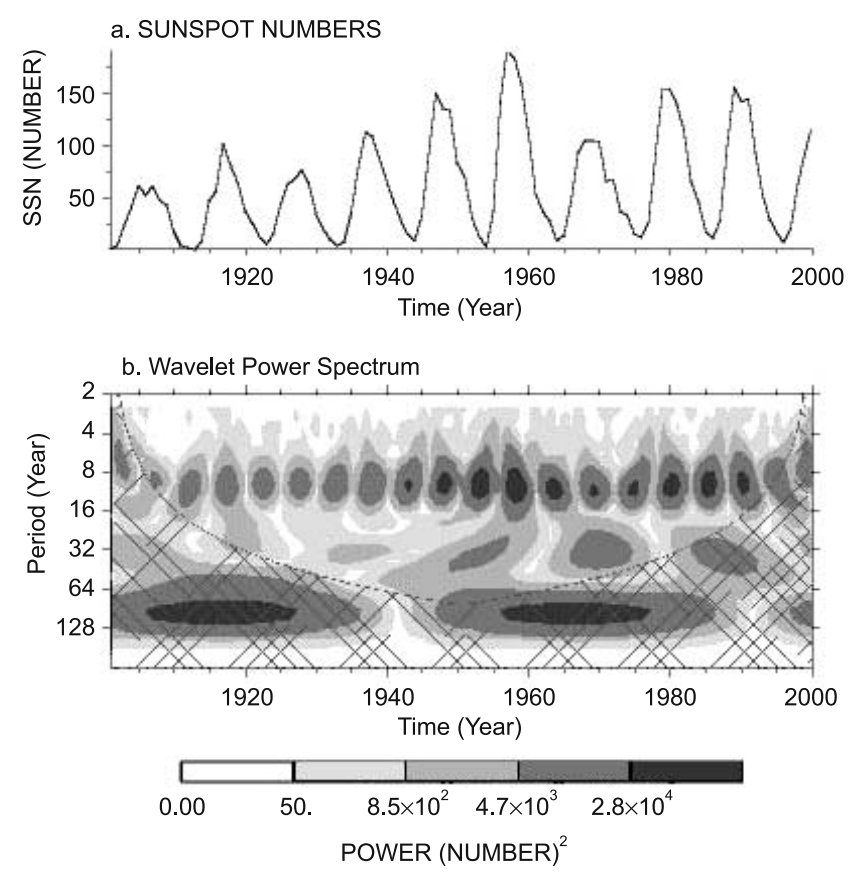

Figure 2. Wavelet analysis of annual sunspot numbers (a) the original time series; (b) wavelet power spectrum; cross-hatched regions on either end indicate the 'cone of influence' where edge effects become important.

Table 1. The results of Fourier analysis of annual precipitation over different regions in years.

\begin{tabular}{ll}
\hline Regions & $\begin{array}{c}\text { Results of fourier analysis } \\
\text { of annual precipitation } \\
\text { in years }\end{array}$ \\
\hline India & \multicolumn{1}{c}{$2.4,2.8,6.6$ and 41.4} \\
Australia & $3.3,3.6,8.4$ and 21.7 \\
Canada & $2,7.3,14.3$ and 23.3 \\
Ethiopia & $3.2,5.2,10.2$ and 40.6 \\
Greenland & $2.8,3.0,3.5$ and 41.4 \\
Iceland & $9.8,11.3,16.7$ and 41.9 \\
Japan & $2.1,3.7,4.4$ and 42.8 \\
Russia & $2.5,4.2$ and 15.8 \\
South Africa & $3.6,11.1,18.7$ and 41.3 \\
UK & $2.2,3.9,6.3$ and 41.3 \\
USA & $3.2,3.7,4.2$ and 11.3 \\
\hline
\end{tabular}

\subsection{Wavelet analysis of precipitation in various regions over the globe}

Fourier analysis of the annual precipitation is calculated here for above-mentioned different geographic regions like sunspot numbers are presented in table 1. Next, Fourier spectra result is compared with the wavelet spectra of precipitation.

Using Fourier techniques, annual precipitation of India finds periods at $2.4,2.8,6.6$ and 41.4 years, represented in figure 3 and also given in table 1. This result supports the wavelet spectra partially. The wavelet spectra of India (figure 4) shows periods $2-6$ years but the power is less intense. Similarly periods around 16 years also shows weak signal.

Like the sunspot numbers and precipitation in India, similar analysis is done for the other stations and the results for Fourier analysis over different stations are presented in table 1. For Australia: Fourier transform of annual precipitation shows $3.3,3.6,8.4$ and 21.7 periodicities, not shown. The wavelet spectra of annual precipitation for Australia reveal that there is no significant power at short periods. Around 1960 and 1980, relatively strong short periodicity is observed. Period greater than 64 years is insignificant as it lies under COI.

The wavelet spectrum of annual precipitation of Canada does not hint to any periods having intense power. But the Fourier analysis results show periods at $2,7.3,14.3$ and 23.3 years.

In Ethiopia, the wavelet results of annual precipitation show periods around 11 years from 19101920. Shorter periods like $3-5$ years are also visible in the beginning of the time series. There are periods greater than 32 years and lies above COI from 1930-1980. Fourier analysis for Ethiopia gives periods at 3.2, 5.2, 10.2 and 40.6 years.

The annual precipitation of Greenland shows shorter periods between 2 and 6 years. The power is intense at the beginning and end of the time series. More intense power is visible but lies near COI, so neglected. This result supports the Fourier spectra at $2.8,3.0,3.5$ and 41.4 years.

The wavelet analysis of annual precipitation for Iceland shows intense power around 16-year periods. Power is also intense around 32-year periods. Wavelet results match well with Fourier at 9.8, $11.3,16.7$ and 41.9 years.

In Japan: annual precipitation shows periods at 2.1, 3.7, 4.4 and 42.8 years after using Fourier transform. Now, wavelet spectrum shows shorter periods but not intense. Intense signal is observed at 11-year periods from 1975 to 2000. Higher order periods are also observed around 43 years but they are insignificant as it lie under the hatched region.

The wavelet results of Russia shows no significant periods, whereas the Fourier analysis results are at $2.5,4.2$ and 15.8 years.

The wavelet analysis of annual precipitation of South Africa hints shorter periods with low power. Higher power around 16-year periodicity is observed. The same time series reveals periods at $3.6,11.1,18.7$ and 41.3 years after Fourier transform.

The wavelet analysis of annual precipitation of UK do not show any significant periods although Fourier analysis as given observes periods at 2.2, 3.9, 6.3 and 41.3 years.

In USA, wavelet study supports the Fourier findings at 3.2, 3.7, 4.2 and 11.3 years. The wavelet 


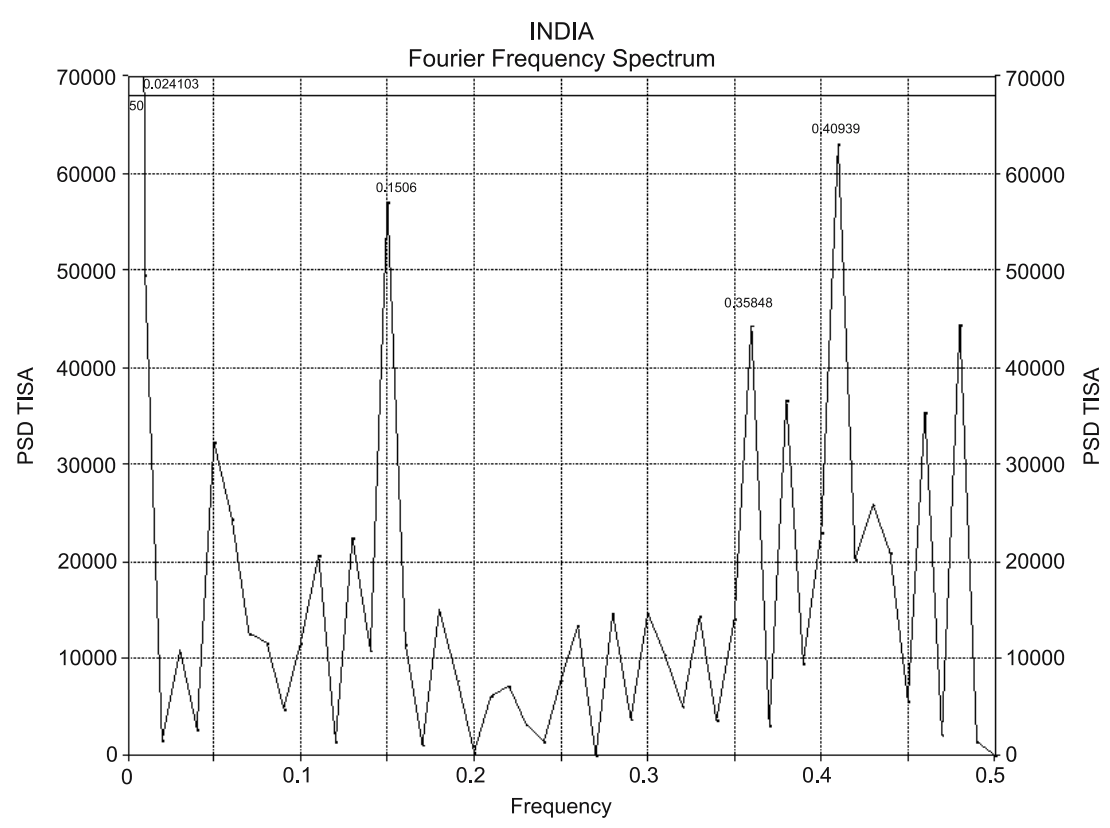

Figure 3. Fourier analysis of annual precipitation in India. The frequency is plotted in x-axis and the power (time integral squared amplitude, TISA) is in y-axis. Annual precipitation in India shows periods at 2.4, 2.8, 6.6 and 41.4 years.
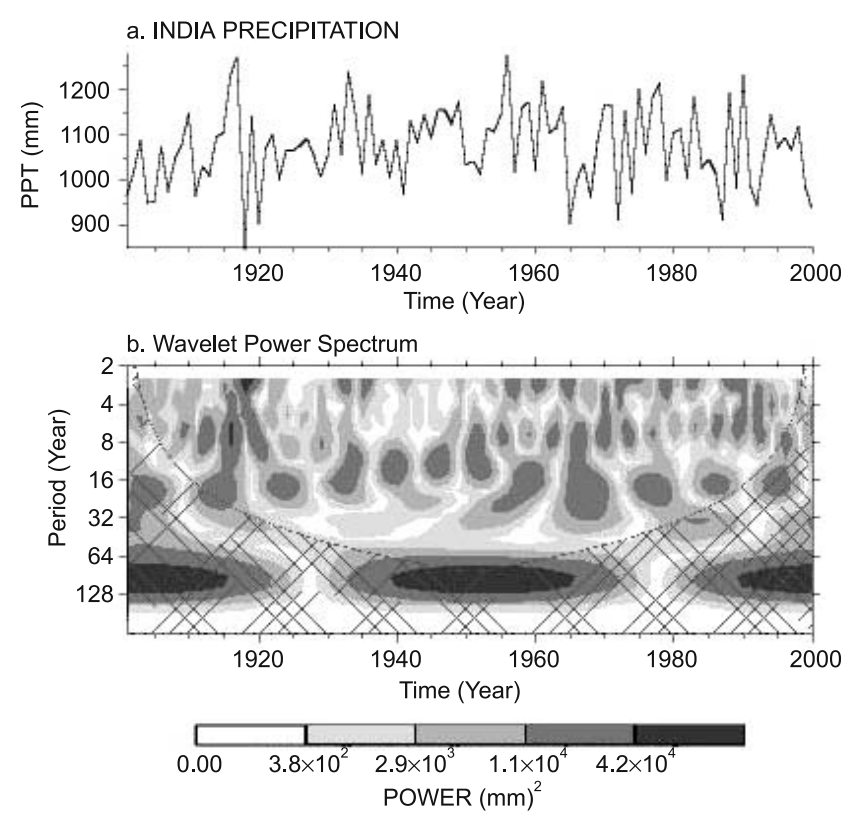

Figure 4. Wavelet analysis of annual precipitation in India (a) the original time series; (b) wavelet power spectrum; cross-hatched regions on either end indicate the "cone of influence' where edge effects become important.

study hints low power periods. The periods are around 4-year and 11-year from 1950 to 1990.

\section{Correlation analysis}

A correlation coefficient is useful first in determining whether a linear relationship between two variables exists and second in providing a measure of the strength of this relationship. It is important to remember that the correlation coefficient between two variables is a measure of their linear relationship, and a value of correlation coefficient equal to zero implies lack of linearity and not a lack of association. In this investigation the most widely used linear correlation between two variables, the Pearson correlation coefficient, is used. The following formula provides a measure of the linear relationship between two variables. Pearson correlation coefficient $(r)$ is in the form:

$$
r=\frac{n \sum x y-\left(\sum x\right)\left(\sum y\right)}{\sqrt{\left[n \sum x^{2}-\left(\sum x\right)^{2}\right]\left[n \sum y^{2}-\left(\sum y\right)^{2}\right]}},
$$

$x, y$ are variables and $n=$ number of variables. In addition to correlation coefficient value we find $p$-value to test for its significance. If this probability is lower than the conventional $5 \%(\alpha<0.05)$ the correlation coefficient is called statistically significant. The significance of correlation is nothing but given by $p$-value. The $p$-value is the observed significance level of the test. If the observed significance level is less than the chosen significance level, $\alpha$ (alpha) equal to 0.05 , then the researcher should reject the null in favour of the alternative. Tables 2, 3 and 4 convey the observation and interested readers would appreciate the results of $p$-values in comparison to $\alpha$ value $<0.05$. If the $p$-value exceeds 0.05 then the correlation is no more significant and do not convey any physics behind it. 
Table 2. The correlation coefficient and significance of the correlation (shown in brackets) between precipitation and any of the following: sunspot, electron fluence, proton fluence at $100 \mathrm{Mev}$. We use the symbol precipitation as PR, sunspot as SSN, electron fluence as E, proton fluence at 100 Mev as P100.

\begin{tabular}{|c|c|c|c|c|c|c|c|}
\hline & $\begin{array}{c}\text { Annual } \\
\text { (PR\&SSN) } \\
(p \text {-value })\end{array}$ & $\begin{array}{c}\text { MAM } \\
\text { (PR\&SSN) } \\
(p \text {-value })\end{array}$ & $\begin{array}{c}\text { JJA } \\
\text { (PR\&SSN }) \\
(p \text {-value })\end{array}$ & $\begin{array}{c}\text { SON } \\
\text { (PR\&SSN) } \\
(p \text {-value })\end{array}$ & $\begin{array}{c}\text { DJF } \\
\text { (PR\&SSN) } \\
(p \text {-value })\end{array}$ & $\begin{array}{l}\text { Annual } \\
\text { (PR\&E) } \\
(p \text {-value })\end{array}$ & $\begin{array}{c}\text { Annual } \\
\text { (PR\&P100) } \\
(p \text {-value })\end{array}$ \\
\hline India & $\begin{array}{c}0.086 \\
(0.39)\end{array}$ & $\begin{array}{c}0.128 \\
(0.21)\end{array}$ & $\begin{array}{c}0.063 \\
(0.53)\end{array}$ & $\begin{array}{c}-0.046 \\
(0.65)\end{array}$ & $\begin{array}{c}-0.099 \\
(0.32)\end{array}$ & $\begin{array}{c}0.203 \\
(0.04)\end{array}$ & $\begin{array}{c}-0.248 \\
(0.01)\end{array}$ \\
\hline Australia & $\begin{array}{c}0.066 \\
(0.51)\end{array}$ & $\begin{array}{c}0.026 \\
(0.80)\end{array}$ & $\begin{array}{c}-0.063 \\
(0.53)\end{array}$ & $\begin{array}{c}-0.077 \\
(0.44)\end{array}$ & $\begin{array}{c}0.054 \\
(0.60)\end{array}$ & $\begin{array}{c}-0.381 \\
(0.0)\end{array}$ & $\begin{array}{c}-0.002 \\
(0.98)\end{array}$ \\
\hline Canada & $\begin{array}{c}0.104 \\
(0.30)\end{array}$ & $\begin{array}{c}0.084 \\
(0.40)\end{array}$ & $\begin{array}{r}0.067 \\
(0.50)\end{array}$ & $\begin{array}{c}0.194 \\
(0.05)\end{array}$ & $\begin{array}{c}0.148 \\
(0.14)\end{array}$ & $\begin{array}{c}0.125 \\
(0.21)\end{array}$ & $\begin{array}{c}-0.016 \\
(0.87)\end{array}$ \\
\hline Ethiopia & $\begin{array}{c}0.066 \\
(0.51)\end{array}$ & $\begin{array}{c}-0.025 \\
(0.80)\end{array}$ & $\begin{array}{c}-0.049 \\
(0.62)\end{array}$ & $\begin{array}{c}-0.073 \\
(0.47)\end{array}$ & $\begin{array}{c}0.163 \\
(0.10)\end{array}$ & $\begin{array}{c}0.010 \\
(0.92)\end{array}$ & $\begin{array}{c}-0.018 \\
(0.85)\end{array}$ \\
\hline Greenland & $\begin{array}{c}-0.001 \\
(0.99)\end{array}$ & $\begin{array}{r}0.157 \\
(0.12)\end{array}$ & $\begin{array}{c}-0.079 \\
(0.43)\end{array}$ & $\begin{array}{c}-0.026 \\
(0.79)\end{array}$ & $\begin{array}{c}0.094 \\
(0.35)\end{array}$ & $\begin{array}{c}-0.531 \\
(0.0)\end{array}$ & $\begin{array}{c}0.157 \\
(0.12)\end{array}$ \\
\hline Iceland & $\begin{array}{c}0.063 \\
(0.53)\end{array}$ & $\begin{array}{c}0.184 \\
(0.06)\end{array}$ & $\begin{array}{c}0.046 \\
(0.64)\end{array}$ & $\begin{array}{c}-0.019 \\
(0.85)\end{array}$ & $\begin{array}{c}0.175 \\
(0.08)\end{array}$ & $\begin{array}{c}-0.398 \\
(0.0)\end{array}$ & $\begin{array}{c}-0.021 \\
(0.83)\end{array}$ \\
\hline Japan & $\begin{array}{c}0.138 \\
(0.17)\end{array}$ & $\begin{array}{c}-0.072 \\
(0.47)\end{array}$ & $\begin{array}{c}0.053 \\
(0.60)\end{array}$ & $\begin{array}{c}0.086 \\
(0.39)\end{array}$ & $\begin{array}{c}0.161 \\
(0.10)\end{array}$ & $\begin{array}{c}-0.534 \\
(0.0)\end{array}$ & $\begin{array}{c}0.090 \\
(0.37)\end{array}$ \\
\hline Russia & $\begin{array}{l}0.359 \\
(0.0)\end{array}$ & $\begin{array}{c}0.171 \\
(0.08)\end{array}$ & $\begin{array}{c}0.263 \\
(0.01)\end{array}$ & $\begin{array}{c}0.229 \\
(0.02)\end{array}$ & $\begin{array}{c}0.222 \\
(0.02)\end{array}$ & $\begin{array}{c}-0.009 \\
(0.93)\end{array}$ & $\begin{array}{c}0.060 \\
(0.55)\end{array}$ \\
\hline South Africa & $\begin{array}{c}-0.035 \\
(0.72)\end{array}$ & $\begin{array}{c}-0.076 \\
(0.45)\end{array}$ & $\begin{array}{c}-0.053 \\
(0.60)\end{array}$ & $\begin{array}{c}-0.037 \\
(0.71)\end{array}$ & $\begin{array}{c}-0.134 \\
(0.18)\end{array}$ & $\begin{array}{c}-0.259 \\
(0.01)\end{array}$ & $\begin{array}{l}0.463 \\
(0.0)\end{array}$ \\
\hline UK & $\begin{array}{r}0.237 \\
(0.02)\end{array}$ & $\begin{array}{c}-0.066 \\
(0.52)\end{array}$ & $\begin{array}{c}0.038 \\
(0.71)\end{array}$ & $\begin{array}{r}0.187 \\
(0.06)\end{array}$ & $\begin{array}{c}0.121 \\
(0.22)\end{array}$ & $\begin{array}{c}-0.083 \\
(0.41)\end{array}$ & $\begin{array}{c}-0.142 \\
(0.16)\end{array}$ \\
\hline USA & $\begin{array}{c}0.202 \\
(0.04)\end{array}$ & $\begin{array}{c}0.197 \\
(0.05)\end{array}$ & $\begin{array}{c}0.240 \\
(0.02)\end{array}$ & $\begin{array}{c}0.141 \\
(0.16)\end{array}$ & $\begin{array}{c}0.104 \\
(0.30)\end{array}$ & $\begin{array}{c}0.163 \\
(0.11)\end{array}$ & $\begin{array}{c}-0.592 \\
(0.0)\end{array}$ \\
\hline
\end{tabular}

Table 3. The correlation coefficient and significance of correlation (shown in brackets) between temperature $(T E)$ and precipitation $(P R)$ for both annual and seasonal components.

\begin{tabular}{|c|c|c|c|c|c|}
\hline & $\begin{array}{c}\text { Annual } \\
\text { (PR\&TE) } \\
(p \text {-value) }\end{array}$ & $\begin{array}{c}\text { MAM } \\
\text { (PR\&TE) } \\
(p \text {-value })\end{array}$ & $\begin{array}{c}\text { JJA } \\
\text { (PR\&TE) } \\
(p \text {-value })\end{array}$ & $\begin{array}{c}\text { SON } \\
\text { (PR\&TE) } \\
(p \text {-value) }\end{array}$ & $\begin{array}{c}\text { DJF } \\
\text { (PR\&TE) } \\
(p \text {-value })\end{array}$ \\
\hline India & $\begin{array}{c}-0.118 \\
(0.24)\end{array}$ & $\begin{array}{c}-0.258 \\
(0.01)\end{array}$ & $\begin{array}{c}-0.513 \\
(0.0)\end{array}$ & $\begin{array}{c}-0.306 \\
(0.0)\end{array}$ & $\begin{array}{c}0.030 \\
(0.76)\end{array}$ \\
\hline Australia & $\begin{array}{c}-0.123 \\
(0.22)\end{array}$ & $\begin{array}{c}-0.098 \\
(0.33)\end{array}$ & $\begin{array}{c}0.194 \\
(0.05)\end{array}$ & $\begin{array}{c}-0.328 \\
(0.0)\end{array}$ & $\begin{array}{c}-0.361 \\
(0.0)\end{array}$ \\
\hline Canada & $\begin{array}{c}0.140 \\
(0.17)\end{array}$ & $\begin{array}{c}0.067 \\
(0.50)\end{array}$ & $\begin{array}{c}0.185 \\
(0.06)\end{array}$ & $\begin{array}{c}-0.281 \\
(0.0)\end{array}$ & $\begin{array}{c}-0.109 \\
(0.28)\end{array}$ \\
\hline Ethiopia & $\begin{array}{c}-0.133 \\
(0.19)\end{array}$ & $\begin{array}{c}-0.244 \\
(0.02)\end{array}$ & $\begin{array}{c}-0.326 \\
(0.0)\end{array}$ & $\begin{array}{c}-0.277 \\
(0.0)\end{array}$ & $\begin{array}{r}-0.131 \\
(0.19)\end{array}$ \\
\hline Greenland & $\begin{array}{c}-0.209 \\
(0.03)\end{array}$ & $\begin{array}{c}-0.072 \\
(0.47)\end{array}$ & $\begin{array}{c}-0.374 \\
(0.0)\end{array}$ & $\begin{array}{c}0.0 \\
(0.99)\end{array}$ & $\begin{array}{c}-0.082 \\
(0.41)\end{array}$ \\
\hline Iceland & $\begin{array}{l}0.280 \\
(0.0)\end{array}$ & $\begin{array}{l}0.285 \\
(0.0)\end{array}$ & $\begin{array}{c}0.228 \\
(0.02)\end{array}$ & $\begin{array}{c}0.149 \\
(0.14)\end{array}$ & $\begin{array}{l}0.358 \\
(0.0)\end{array}$ \\
\hline Japan & $\begin{array}{c}0.106 \\
(0.29)\end{array}$ & $\begin{array}{l}0.302 \\
(0.0)\end{array}$ & $\begin{array}{c}-0.465 \\
(0.0)\end{array}$ & $\begin{array}{c}0.219 \\
(0.02)\end{array}$ & $\begin{array}{l}0.370 \\
(0.0)\end{array}$ \\
\hline Russia & $\begin{array}{c}0.196 \\
(0.05)\end{array}$ & $\begin{array}{l}0.435 \\
(0.0)\end{array}$ & $\begin{array}{r}-0.007 \\
(0.94)\end{array}$ & $\begin{array}{c}0.094 \\
(0.35)\end{array}$ & $\begin{array}{c}0.308 \\
(0.02)\end{array}$ \\
\hline South Africa & $\begin{array}{c}-0.249 \\
(0.01)\end{array}$ & $\begin{array}{c}-0.440 \\
(0.0)\end{array}$ & $\begin{array}{c}-0.190 \\
(0.05)\end{array}$ & $\begin{array}{c}-0.222 \\
(0.02)\end{array}$ & $\begin{array}{c}-0.376 \\
(0.0)\end{array}$ \\
\hline UK & $\begin{array}{c}0.077 \\
(0.44)\end{array}$ & $\begin{array}{c}-0.163 \\
(0.10)\end{array}$ & $\begin{array}{c}-0.566 \\
(0.0)\end{array}$ & $\begin{array}{c}-0.005 \\
(0.95)\end{array}$ & $\begin{array}{l}0.446 \\
(0.0)\end{array}$ \\
\hline USA & $\begin{array}{c}0.079 \\
(0.43)\end{array}$ & $\begin{array}{c}-0.096 \\
(0.34)\end{array}$ & $\begin{array}{c}-0.419 \\
(0.0)\end{array}$ & $\begin{array}{c}-0.202 \\
(0.04)\end{array}$ & $\begin{array}{c}-0.049 \\
(0.62)\end{array}$ \\
\hline
\end{tabular}


Table 4. The correlation coefficient and significance of correlation (shown in brackets) between precipitation $(P R)$ and cloud cover $(C C)$ for both annual and seasonal components.

\begin{tabular}{|c|c|c|c|c|c|}
\hline & $\begin{array}{c}\text { Annual } \\
\text { (PR\&CC) } \\
(p \text {-value) }\end{array}$ & $\begin{array}{c}\text { MAM } \\
\text { (PR\&CC) } \\
(p \text {-value) }\end{array}$ & $\begin{array}{c}\text { JJA } \\
\text { (PR\&CC) } \\
(p \text {-value })\end{array}$ & $\begin{array}{c}\text { SON } \\
\text { (PR\&CC) } \\
(p \text {-value })\end{array}$ & $\begin{array}{c}\text { DJF } \\
\text { (PR\&CC) } \\
(p \text {-value })\end{array}$ \\
\hline India & $\begin{array}{r}0.323 \\
(0.0)\end{array}$ & $\begin{array}{r}0.370 \\
(0.0)\end{array}$ & $\begin{array}{r}0.386 \\
(0.0)\end{array}$ & $\begin{array}{r}0.373 \\
(0.0)\end{array}$ & $\begin{array}{r}0.471 \\
(0.0)\end{array}$ \\
\hline Australia & $\begin{array}{r}0.701 \\
(0.0)\end{array}$ & $\begin{array}{r}0.685 \\
(0.0)\end{array}$ & $\begin{array}{c}0.804 \\
(0.0)\end{array}$ & $\begin{array}{r}0.779 \\
(0.0)\end{array}$ & $\begin{array}{r}0.706 \\
(0.0)\end{array}$ \\
\hline Canada & $\begin{array}{r}0.647 \\
(0.0)\end{array}$ & $\begin{array}{r}0.429 \\
(0.0)\end{array}$ & $\begin{array}{r}0.644 \\
(0.0)\end{array}$ & $\begin{array}{r}0.602 \\
(0.0)\end{array}$ & $\begin{array}{r}0.380 \\
(0.0)\end{array}$ \\
\hline Ethiopia & $\begin{array}{r}-0.014 \\
(0.89)\end{array}$ & $\begin{array}{r}0.123 \\
(0.22)\end{array}$ & $\begin{array}{r}-0.059 \\
(0.56)\end{array}$ & $\begin{array}{c}0.224 \\
(0.02)\end{array}$ & $\begin{array}{r}-0.079 \\
(0.43)\end{array}$ \\
\hline Greenland & $\begin{array}{r}0.249 \\
(0.01)\end{array}$ & $\begin{array}{r}0.107 \\
(0.29)\end{array}$ & $\begin{array}{r}0.411 \\
(0.0)\end{array}$ & $\begin{array}{r}0.329 \\
(0.0)\end{array}$ & $\begin{array}{r}0.156 \\
(0.12)\end{array}$ \\
\hline Iceland & $\begin{array}{r}0.148 \\
(0.14)\end{array}$ & $\begin{array}{r}0.276 \\
(0.0)\end{array}$ & $\begin{array}{r}0.167 \\
(0.09)\end{array}$ & $\begin{array}{c}0.134 \\
(0.18)\end{array}$ & $\begin{array}{r}0.302 \\
(0.0)\end{array}$ \\
\hline Japan & $\begin{array}{r}0.541 \\
(0.0)\end{array}$ & $\begin{array}{r}0.545 \\
(0.0)\end{array}$ & $\begin{array}{r}0.745 \\
(0.0)\end{array}$ & $\begin{array}{r}0.517 \\
(0.0)\end{array}$ & $\begin{array}{r}0.524 \\
(0.0)\end{array}$ \\
\hline Russia & $\begin{array}{r}-0.157 \\
(0.11)\end{array}$ & $\begin{array}{r}0.217 \\
(0.03)\end{array}$ & $\begin{array}{r}-0.186 \\
(0.06)\end{array}$ & $\begin{array}{r}0.237 \\
(0.01)\end{array}$ & $\begin{array}{r}0.318 \\
(0.0)\end{array}$ \\
\hline South Africa & $\begin{array}{r}0.500 \\
(0.0)\end{array}$ & $\begin{array}{r}0.663 \\
(0.0)\end{array}$ & $\begin{array}{r}0.442 \\
(0.0)\end{array}$ & $\begin{array}{r}0.423 \\
(0.0)\end{array}$ & $\begin{array}{r}0.653 \\
(0.0)\end{array}$ \\
\hline UK & $\begin{array}{r}0.122 \\
(0.22)\end{array}$ & $\begin{array}{r}0.427 \\
(0.0)\end{array}$ & $\begin{array}{r}0.598 \\
(0.0)\end{array}$ & $\begin{array}{r}0.145 \\
(0.15)\end{array}$ & $\begin{array}{r}-0.027 \\
(0.78)\end{array}$ \\
\hline USA & $\begin{array}{r}0.578 \\
(0.0)\end{array}$ & $\begin{array}{r}0.510 \\
(0.0)\end{array}$ & $\begin{array}{r}0.502 \\
(0.0)\end{array}$ & $\begin{array}{r}0.726 \\
(0.0)\end{array}$ & $\begin{array}{r}0.393 \\
(0.0)\end{array}$ \\
\hline
\end{tabular}

The investigation is continued with calculation of correlation between the datasets of sunspot numbers, precipitation, temperature, and cloud cover, electron fluence and proton fluence. From table 2, we find maximum positive correlation coefficient, i.e., $0.350,0.237$ and 0.202 between annual sunspot numbers and annual precipitation over Russia, UK and USA, respectively. Negative correlation coefficients are observed at Greenland and South Africa but statistically insignificant. The value of correlation coefficient between sunspot and precipitation in seasonal scale are always positive at Russia and USA. In South Africa though insignificant, we find negative correlation in all seasonal months. The correlation coefficient between precipitation and electron fluence as given in table 2 shows negative value at Greenland, Japan, Iceland, Australia and South Africa and directly related in India. Similarly high inverse relation between precipitation and proton fluence are observed in USA (P100) and India (P100). We have an interesting result showing that in South Africa (P100) a positive correlation exists. Correlation coefficient between precipitation and temperature in annual combination hints negative value in India, Australia, Ethiopia, Greenland and South Africa as given in table 3 . In seasonal combination, $r$ value between precipitation and temperature gives negative value in India (JJA), Australia (DJF), Ethiopia (JJA), Japan (JJA), South Africa (DJF), UK (JJA) and USA (JJA). Investigation is continued between cloud cover and precipitation in both annual and seasonal time scales (table 4). As expected, $r$ values are positive in almost all regions with exception in Ethiopia (annual, JJA, and DJF), Russia (annual, JJA). Maximum positive correlation coefficients are observed in Australia, Canada, India, Japan, South Africa and USA. Finally the $p$-values along with $r$ values as shown in tables $2-4$ are less than 0.05 in most cases and do not hint a linear relation between Sun and climatic parameters.

\section{Conclusion and discussions}

The present paper is an attempt to quantify the relation between Sun and climatic parameters. The wavelet analysis shows almost all kinds of periodicities on one time or other ranging from 2 to 11 years and more. Therefore, it should be further studied to investigate any quantitative effect of solar activity on other parameters. The correlation coefficient calculated in tables $2-4$ indicates the $r$ values are low valued in most of the cases. In addition, the significance of correlation ( $p$-value) 
shows that most of the $r$ values may not have their origin in physical process. Moreover, these findings are of global nature and do not furnish us precise information about how such relation occurs. Similar periodicities does not necessarily implies that one is the cause and the other the effect; besides even if the correlation coefficient is very low, that does not mean that there is no relation. In fact there is the possibility that such a relation could be of non-linear in nature or that there is a strong phase shift between the parameters. The spectral analysis that is used to investigate common periodicities between two series of data is the Fourier transform. However, it is useful for stationary time series whereas wavelet technique is appropriate for non-stationary time series. The 100-year time series of the total annual precipitation, observed in different geographic regions are analyzed using classical and wavelet analysis. The main findings are: the wavelet spectrum of annual precipitation shows short dominant periods $(2-6$ years) over many regions except Russia, Canada and UK. Power signal around 10-11 year were also observed in certain areas on the globe. These results are in good agreement with Fourier analysis. Also there are periods around 16-32 years and 40-60 years, while studying annual precipitation over few geographic locations. Similarly, sunspot numbers also show strong periodicity around 9-11 years and these two time series over different locations share common periods like ( $2-6$ years) and (9-11 years), using Fourier transform. The wavelet transforms of annual precipitation of few countries like USA, Ethiopia and Japan show 9-11 year periodicity. The brief discussion of the results of wavelet transform implies that oscillations of annual precipitation on different regions are likely driven, at least partly, by solar variability. The general correspondence of prominent precipitation changes in certain area to variations in solar activity implies a solar influence on area-scale precipitation oscillations during the past 100 years, although here the suggested correlation is limited to a pure qualitative point of view. At present, we are in doubt that how the periodicity variation of solar activity influences precipitation on land. Electron and proton fluence may be considered as a source of either solar energetic particle or galactic cosmic rays. Since, galactic cosmic rays are anticorrelated with sunspot activity, one would expect that any increase in solar activity results in seemingly decreasing the intensity of galactic cosmic flux. This ultimately results in both reducing the activity in nucleation of cloud particles and suppressing the precipitation (Parker 1999). Therefore, in most of the findings we have negative correlation coefficients between precipitation with electron and proton fluence. It is expected that $r$ is positive between precipitation and solar activity in annual and seasonal scales. The observed negative $r$ value may be due to changes in spatial and the temporal occurrence pattern of the aerosol particles either due to volcanic eruptions or due to interstellar dust particles in the atmosphere (Hiremath and Mandi 2004; Hiremath 2006). Our work estimates, as expected, that correlation coefficient between temperature and precipitation is negative. The explanation for this may be due to the fact that precipitation reduces the temperature locally. In few regions, and seasonal combinations, the positive $r$ value may be due to low temperature regions or months. The correlation of cloud cover with precipitation should have high $r$ value (Dickinson 1975) and our study shows similar result as cloud cover-precipitation relation is highly correlated in majority (table 4). In this paper an attempt was made to study the relationship between precipitation, solar activity, cloud cover, temperature, electron and proton influence in different geographical regions. The correlative and wavelet analysis of 100 years data of the sunspot and precipitation in different geographical region over the globe have been done. We conclude that positive as well as negative correlation coefficient exists between precipitation and solar activity in different areas of investigation. We also find correlation and anticorrelation for seasonal precipitation, solar activity in different countries around the world.

Our work supports (Clayton 1923; Xanthakis 1973; Hiremath and Mandi 2004; Hiremath 2006) that there is probably an influence of solar activity on the annual precipitation in almost all the geographic regions around the globe. Variation of solar activity reaching the Earth is thought to influence precipitation, but we are still searching for better physics to understand how the periodic variation of the solar activity influences the variation of the precipitation of land.

Finally, we have observed that precipitation over different geographic regions is more significant with short periods like 2-6 years than 11, 22 or higher order periods. This indicates that the Sun-climate mechanism is important for precipitation variability at different areas. In conclusion, the phenomenon that seems to be influencing precipitation is the solar activity but it is indirectly affecting the system and may not have their origin in physical processes. Possible non-linear effects of solar variability, local phenomenon or factors and natural phenomenon may contribute significantly to the regional precipitation variability and should be further studied. 


\section{Acknowledgement}

We are extremely thankful to the referee for his/her valuable suggestions.

\section{References}

Bazilevskaya G A 2000 Observation of variability in cosmic rays; Space Sci. Rev. 94 25-38.

Clayton H H 1923 World weather including a discussion of the influence of solar radiations on the weather; (New York: Macmillan).

Dickinson R E 1975 Solar variability and the lower atmosphere; Bull. Am. Meteor. Soc. 56 1240-1248.

Echer Souza M P, Echer E, Nordemann D J, Rigozo N R and Prestes A 2008 Wavelet analysis of a centennial (1895-1994) southern Brazil rainfall series; Climatic Change 87 489-497.

Eddy J A 1976 The Maunder minimum; Science 192 $1189-1202$

Hiremath K M and Mandi P I 2004 Influence of the solar activity on the Indian Monsoon rainfall; New Astronomy 9651.

Hiremath K M 2006 The influence of solar activity on the rainfall over India: Cycle to cycle variations; J. Astrophys. Astr. 27 367-372.

Mitchell T D, Hulme M and New M 2002 Climate data for political areas; Area 109-112.

Mitchell T D, Carter T R, Jones P D, Hulme M and New M 2004 A comprehensive set of high resolution grids of monthly climate for Europe and the globe: The observed record (1901-2000) and 16 scenarios (2001-2100) Tyndall Centre for Climate Change Research, Working paper 55.
Mitchell T D and Jones P D 2005 An improvement method of constructing a database of monthly climate of observations and associated high resolution grids; Int. J. Climatol. 25 693-712.

Reid G C 1991 Solar total irradiance variation and the global sea surface temperature record; J. Geophys. Res. $962835-2844$.

Reid G C 1999 Solar variability and its implication for the human environment; J. Atmos. Terr. Phys. 61 3-14.

Solanki S K and Fligge M 1999 A reconstruction of total solar irradiance since 1700; Geophys. Res. Lett. 26 $2465-2468$.

Svensmark H and Friis-Christensen E 1997 Variation of cosmic ray flux and global cloud coverage - a missing link in solar-climate relationships; J. Atmos. Terr. Phys. 59 $1225-1232$.

Svensmark H 1998 Influence of cosmic rays on Earth's climate physics; Rev. Lett. 81 5027-5030.

Torrence C and Compo G 1998 A practical guide to wavelet analysis; Bull. Amer. Met. Soc. 79 61-78.

Usoskin G I and Kovaltsov A G 2008 Cosmic rays and climate of the Earth: Possible connection; C.R. Geosci. 340 $441-450$

Verschuren D, Laird K R and Cumming B F 2000 Nature 403410.

Xanthakis J 1973 Solar activity and precipitation; In: Solar activity and related interplanetary and terrestrial phenomena (ed.) Xanthakis J, Springer, Berlin 20.

Zhao J, Han Y B and Li Z A 2004 The effect of solar activity on the annual precipitation in the Beijing area; Chin. J. Astron. Astrophys. 4(2) 189-197.

Zhao J and Han Y B 2005 Determination of precipitation cycle in Beijing area and comparison with solar activity cycle; Earth, Moon and Planets 97 69-78. 